\title{
SYNTHESIS AND CHARACTERIZATION OF MANGANESE-GLYCINE AND COPPER-GLYCINE ADDUCTS
}

\author{
Robson Fernandes de Farias* \\ Departamento de Química, Universidade Federal de Roraima, CP 167, 69301-970 Boa Vista - RR
}

Recebido em 11/6/01; aceito em 20/2/02

\begin{abstract}
This work reports the synthesis and characterization of adducts of general formula $\mathrm{MCl}_{2} \cdot n g l y$, where $\mathrm{M}=\mathrm{Mn}$ and $\mathrm{Cu} ; \mathrm{n}=2$ and 4 , and gly= glycine. The manganese adducts were synthesized by dissolution of both, manganese chloride and glycine in water, whereas the copper adducts were obtained by using an alternative solid state synthesis approach. For all adducts, the obtained infrared data shows that the coordination involves the amine nitrogen atom, as well as an oxygen atom of the $\mathrm{COO}^{-}$group. The TG curves for the synthesized adducts exhibit only one mass loss step associated with the release of glycine molecules.
\end{abstract}

Keywords: glycine; copper; manganese; adducts.

\section{INTRODUCTION}

Twenty natural amino acids comprise the building blocks of proteins, which are chemical species indispensable to perform a huge number of biological functions, as exemplified by the role of enzimes ${ }^{1}$.

Glycine $\left({ }^{+} \mathrm{H}_{3} \mathrm{NCH}_{2} \mathrm{COO}^{-}\right)$is the simplest one among the twenty natural amino acids, representing approximately one-third of the collagen composition. However, its hydrogen atom is less available to act as hydrogen bond former ${ }^{1}$.

The oxygen and nitrogen basic centres in the structures of amino acids enable them to act as potential sites for binding metal ions. This behaviour is more pronounced with the third row elements ${ }^{2}$. On this account, the cadmium-glycine interactions have been studied ${ }^{3,4}$.

The aim of this publication is to report the synthesis and characterization of adducts of general formula $\mathrm{MCl}_{2}$.ngly, where $\mathrm{M}=$ $\mathrm{Mn}$ and $\mathrm{Cu} ; \mathrm{n}=2$ and 4, and gly= glycine. It is worth noting that the compounds synthesized and studied here are adducts, with neutral glycine molecules, and not complexes with the glycinate anion ${ }^{5,6}$, as in $\mathrm{Cu}(\mathrm{gly})_{2}$.

\section{EXPERIMENTAL}

Manganese-glycine adducts were synthesized by dissolving $\mathrm{MnCl}_{2}$ (Merck) and glycine (Merck) in bidistilled water, using the desired stoichiometric ratio. The solutions thus obtained were mixed and the solvent slowly evaporated by heating the mixture to $30{ }^{\circ} \mathrm{C}$. After the solvent evaporation was completed (5-15 days), the adducts were dried under vacuum at room temperature for $36 \mathrm{~h}$. The syntheses were performed in aqueous media in an attempt to reproduce the composition and $\mathrm{pH}$ of a biological medium.

Copper-glycine adducts were synthesized by using $\mathrm{CuCl}_{2}$ (Aldrich) and glycine (Merck) both of analytical grade. The adducts were prepared by solid state mechanically induced reaction, by grinding stoichiometric amounts of the metal halide and amino acid in a mortar for $70 \mathrm{~min}$. A comparison of the IR spectra of free amino acid and adducts, confirms that no free ligand molecules were present after the grinding procedure. This solid state approach was employed due to the fact that the copper-glycine adducts prepared by the same

*e-mail: robdefarias@bol.com.br synthetic route employed for the manganese-glycine adducts were so difficult to be dried at room temperature. On the other hand, the solid state reaction procedure employed to obtain such compounds has been successful, yielding adducts with only a minor amount of adsorbed water, which was removed under vacuum at room temperature for $24 \mathrm{~h}$.

Carbon, nitrogen and hydrogen contents were determined using a Perkin-Elmer microelemental analyser. The infrared spectra were recorded with a Bomem apparatus in the $4000-400 \mathrm{~cm}^{-1}$ range, with a resolution of $4 \mathrm{~cm}^{-1}$. The spectra were obtained from powders in $\mathrm{KBr}$ discs for all the adducts. Thermogravimetric (TG) curves were obtained with a Shimadzu TGA 50 apparatus under argon atmosphere with a heating rate of $5^{\circ} \mathrm{C} \mathrm{min}^{-1}$.

\section{RESULTS AND DISCUSSION}

The CHN elemental analysis results as well as the proposed formulas for the adducts obtained are summarized in Table 1. The results obtained are in good agreement with the expected stoichiometries for the adducts. The main infrared bands are shown in Table 2 .

Table 1. Experimental and calculated (\%) values of carbon, nitrogen and hydrogen elemental analysis results for manganese-glycine and copper-glycine adducts

\begin{tabular}{lcrc}
\hline proposed formula & carbon/\% & nitrogen/\% & hydrogen/\% \\
\hline $\mathrm{MnCl}_{2} .2$ gly & $17.5(17.4)$ & $9.6(10.1)$ & $3.4(3.6)$ \\
$\mathrm{MnCl}_{2}$.4gly & $22.4(22.5)$ & $12.7(13.2)$ & $4.7(4.7)$ \\
$\mathrm{CuCl}_{2} .2 \mathrm{gly}$ & $16.9(16.8)$ & $10.1(9.8)$ & $3.7(3.5)$ \\
$\mathrm{CuCl}_{2} .4 \mathrm{gly}$ & $21.5(22.1)$ & $12.0(12.8)$ & $4.7(4.6)$ \\
\hline
\end{tabular}

Table 2. Main infrared bands $/ \mathrm{cm}^{-1}$ for manganese-glycine and copper-glycine adducts

\begin{tabular}{lcc}
\hline compound & $v_{\mathrm{a}}\left(\mathrm{COO}^{-}\right)$ & $v_{\mathrm{s}}\left(\mathrm{COO}^{-}\right)$ \\
\hline glycine & 1596 & 1412 \\
$\mathrm{MnCl}_{2} \cdot 2$ gly & $1635 / 1571$ & 1410 \\
$\mathrm{MnCl}_{2} \cdot 4$ gly & $1635 / 1575$ & 1409 \\
$\mathrm{CuCl}_{2} .2$ gly & 1655 & 1408 \\
$\mathrm{CuCl}_{2} \cdot 4$ gly & $1652 / 1615$ & $1408 / 1418$ \\
\hline
\end{tabular}


For free glycine, the main infrared bands are the $v_{\mathrm{a}}\left(\mathrm{COO}^{-}\right)$and the $v_{\mathrm{s}}\left(\mathrm{COO}^{-}\right)$, located at 1596 and $1412 \mathrm{~cm}^{-1}$, respectively ${ }^{4}$. For the $\mathrm{MnCl}_{2}$.ngly adducts the same sequence of bands is shifted to 1635 and $1410 \mathrm{~cm}^{-1}(\mathrm{n}=2)$, and 1635 and $1409 \mathrm{~cm}^{-1}(\mathrm{n}=4)$. The frequency due to the antisymmetric vibrational mode increases whereas that due to the symmetric vibrational mode decreases, indicating that the coordination involves the amine nitrogen atom, as well as an oxygen atom of the $\mathrm{COO}^{-}$group ${ }^{7}$. Similar arguments can be used for the copper-glycine adducts. The splitting of the bands due to the antisymmetric vibrational modes observed for the manganese and $\mathrm{CuCl}_{2} .4$ gly adducts, suggests a strong metal-amino acid interaction for these compounds. The larger $\Delta v$ (antisymmetric-symmetric) infrared separations for copper adducts, could be understood as the consequence of a stronger copper-glycine interaction ${ }^{7}$, in comparison with the manganese-glycine one. Such a fact is in agreement with a larger charge/radius ratio for $\mathrm{Cu}^{2+}$. As an illustrative example, the infrared spectrum for $\mathrm{CuCl}_{2} .4 \mathrm{gly}$ is shown in Figure 1 .

The proposed formulas based on the elemental analysis results are in acceptable agreement with the calculated mass loss $( \pm 7 \%)$

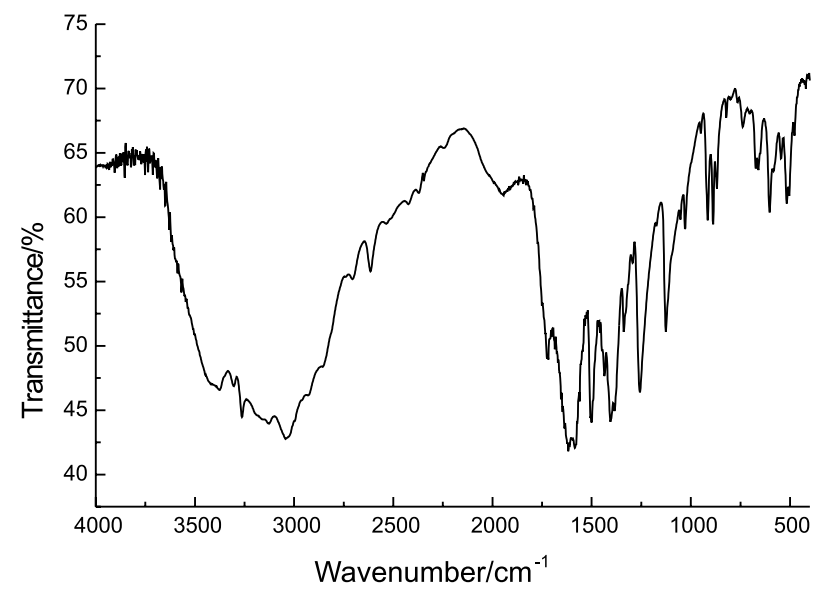

Figure 1. Infrared spectrum for $\mathrm{CuCl}_{2} .4 \mathrm{gly}$ due to the release of glycine molecules, as determined from thermogravimetric data. The TG curves for the synthesized adducts exhibit only one mass loss step associated with the release of glycine molecules. The adducts begins their thermal degradations at $145^{\circ} \mathrm{C}$ $\left(\mathrm{CuCl}_{2} \cdot 2 \mathrm{gly}\right), 160{ }^{\circ} \mathrm{C}\left(\mathrm{CuCl}_{2} \cdot 4 \mathrm{gly}\right), 210{ }^{\circ} \mathrm{C}\left(\mathrm{MnCl}_{2} \cdot 4 \mathrm{gly}\right)$ and $240{ }^{\circ} \mathrm{C}\left(\mathrm{MnCl}_{2} .2 \mathrm{gly}\right)$, respectively. As an illustrative example, the $\mathrm{TG}$ and DTG curves for $\mathrm{MnCl}_{2} .2 \mathrm{gly}$ are shown in Figure 2.

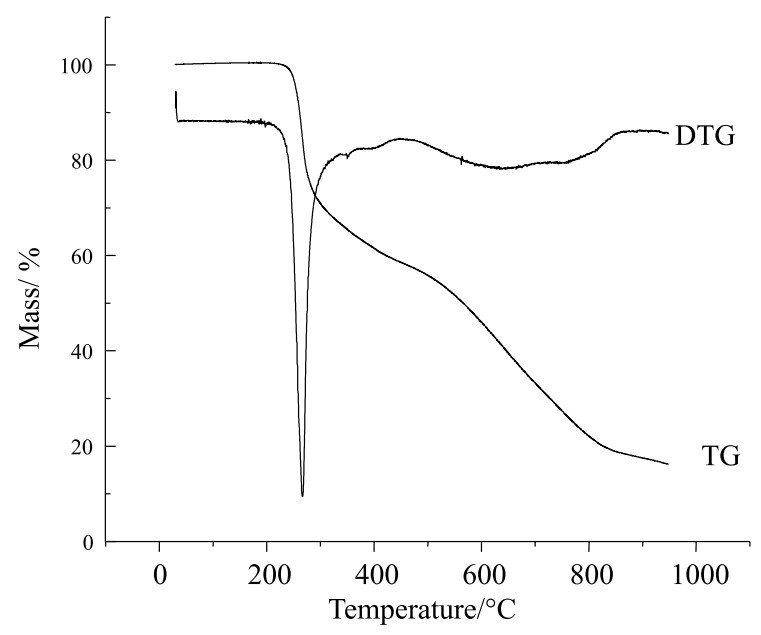

Figure 2. TG and DTG curves for $\mathrm{MnCl}_{2} .2 \mathrm{gly}$

\section{REFERENCES}

1. Garret, R. H.; Grisham, C. M.; Biochemistry, Saunders: New York, 1995.

2. da Silva, J. J. R. F.; Williams, R. J. P.; The Biological Chemistry of the Elements, Oxford University Press: Oxford, 1991.

3. de Farias, R. F.; Scatena Jr., H.; Airoldi, C.; J. Inorg. Biochem. 1999, 73, 253.

4. de Farias, R. F.; Airoldi, C.; J. Inorg. Biochem. 1999, 76, 273.

5. da Silva, M. A. V. R.; da Silva, M. D. M. C. R.; Bernardo, M. M. C.; Santos, L. M. N. B. F.; Thermochim. Acta 1992, 205, 113.

6. O'Brien, P.; J. Chem. Educ. 1982, 59, 1052.

7. Nakamoto, K.; Infrared and Raman Spectra of Inorganic and Coordination Compounds, $4^{\text {th }}$ ed., John Wiley \& Sons: New York, 1986. 